It will be easy to criticize the new ninth edition of Vorländer as superficial, but actual use will prove it to be sound and reliable. It strikes at the truly climactic points of western philosophy, and constant revision has endowed it with utmost clarity and precision. Any library would be well advised to check the bibliographies against its catalog.-Lawrence S. Thompson, University of Kentucky Libraries.

\section{International Relations}

Training of Specialists in International Relations. By C. Dale Fuller. Washington: American Council on Education, 1957. 136p. $\$ 3.00$.

This analysis of current graduate programs available to would-be specialists in international relations has a three-fold interest for librarians. The author, who is chairman of the Department of International Relations at the University of Denver, defines the field, sketches the programs offered and analyzes their strength and weakness.

The librarian-educator who has the responsibility of furnishing materials and services to the faculty members and students in the field of international relations will gain from this study an understanding of the breadth and variety of their interests. A large percentage of the graduates specializing in international relations emerge as teachers. They in turn will make demands on college and university libraries. Implied, although not specifically mentioned, is the fact that the extent to which they have learned during their training period to use library resources effectively, will in turn affect the use that their students will make of academic libraries. The literature of international relations is so vast that students need training in the identification, selection, and organization of appropriate references. In the chapter devoted to the strengths and weaknesses of this specialized training there are found some hints to librarians where former students suggest a need for training in the techniques of fact finding, of individual reading programs to fill in gaps, and a desire for courses in the related fields of geog- raphy, economics, and the behavioral sciences. Some respondents suggest that lengthy theses are less desirable than training in how to assemble material and prepare a concise analysis.

For the librarian-professor concerned with training future members of our profession this volume offers soul-searching suggestions, for, like the international relations expert, the librarian is both a generalist and a specialist whose formal period of instruction is only the beginning of his professional training. One might substitute "librarianship" in the sentence "Graduate training in international relations is designed to reduce the distortion which is inevitable in over-specialization, while at the same time giving focus to broader education." (p. 127) Both fields need cooperative courses, seminars, and individual reading programs to supplement previously acquired knowledge. Likewise, the multidisciplinary nature of the field suggests that the students selected for training be restricted to those with outstanding undergraduate records and broad general education. The personal characteristics of flexibility, sensitivity, capacity to endure frustration, ability to submit to detailed supervision, and work without public acclaim are desirable in many library situations. Admissions officers of library schools might well ponder the sentence "One can infer much about a person from a written statement as to why he wishes to undertake graduate instruction in international relations." (p. 124)

Among the specialists engaged in international relations are librarians who serve the United States Information Agency in this country and overseas. Over and above their professional competence as librarians these individuals need to possess additional skills and personal characteristics. "Individuals who are personally dissatisfied with their assignments abroad tend to be those who have no language skill and by reason of this deficiency have become isolated socially from the citizens of the country in which they are stationed." (p. 47-8) The very nature of the work of overseas librarians demands daily contact with local nationals and language ability to enable them to gain the confidence of their library users. Among the added personal characteristics for overseas positions are ability to select, train, and evaluate the 
work of locally recruited personnel, a sense of humor and proportion, good health, and the ability to adapt to a new environment. To paraphrase Professor Fuller-For the librarian abroad, his own and his family's behavior may be the principal means by which those with whom he comes in contact form an image of Americans and American librarianship.-Flora B. Ludington, Mount Holyoke College.

\section{Catalog Code Revision}

Toward a Better Cataloging Code; Papers presented before the Twenty-first Annual Conference of the Graduate Library School of the University of Chicago, June 13-15, 1956. Ed. by Ruth French Strout. Chicago: University of Chicago Press, 1957. 116p. $\$ 3.75$.

These papers from the Graduate Library School Conference treat the subject of cata$\log$ code revision from various points of view; the historical background (Ruth French Strout and Paul S. Dunkin), "general considerations on the function and content of catalog entries" (Richard S. Angell), problems in applying catalog codes (Herman H. Henkle and Benjamin A. Custer), the cost of cataloging (Raynard C. Swank), developments in other countries (Andrew D. Osborn and Arthur H. Chaplin), and the present state of code revision in the United States (Seymour Lubetzky and Wyllis E. Wright).

The papers by Strout and Dunkin trace the history of catalog codes from 2000 B.c. to the present. Strout concludes her account by asserting: "Throughout history codes seem always to have envisaged catalogs which were far better than their contemporary catalogs ever were ... Codes have not been a statement of the usages of their day but rather the very means through which progress has come." Dunkin details the attacks on catalog codes of the past fifteen years, beginning with Osborn's "The Crisis in Cataloging," pointing out that the attacks have ranged around three subjects: basic principles, simplification, and study of the user. He notes that today the "crisis in cataloging" has become a part of the larger crisis in public and academic library administration generally and bibliographical control in general and wisely observes that agreement on functions is much easier to come by than agreement on techniques to implement functions.

In his attempt to develop "some general considerations on the function and content of catalog entries," Angell takes a close look at some of the basic principles (and alleged lack thereof) of our present codes, both for entry and for descriptive cataloging. His criticism is frequently sharp and incisive and will stimulate, if not antagonize, most readers. He contends that the rules for cataloging books have been too slavishly followed in devising rules for other media of communication and suggests that it is possible to devise rules for entry of the various media which grow "naturally" out of the media themselves. Unfortunately, there is no extended discussion of this point, and no illustrations of specific rules are presented for our consideration. He also contends that our rules are weak in conveying the import of the communication, implying that we should not rely on subject headings for this necessary function. These points are typical of many others in an essay which attempts to extend the frame of reference of code revision considerably beyond its usual boundaries.

Custer attempts to identify some of the most pressing problems in public libraries, as distinguished from academic libraries, e.g., the effect of filing rules on the rules of entry and on use of the catalog, the greater use of "common" rather than "authoritative" names, the probably greater use by patrons of names and titles as they appear on the works being cataloged, and the need for less detailed descriptive cataloging rules.

Henkle is particularly concerned with the problems of application of rules and suggests that the shift from the legalistic to the pragmatic theory in descriptive cataloging has perhaps been in name only-that operational research is needed to determine how far practicing catalogers have actually changed their point of view. At the same time, he points out that practicing catalogers have a unique opportunity to contrib- 